\title{
Native T1 mapping in children and young adults with hypertrophic cardiomyopathy
}

\author{
Keyur Parekh*, Michael Markl, Jie Deng, Roger A de Freitas, Cynthia K Rigsby \\ From 19th Annual SCMR Scientific Sessions \\ Los Angeles, CA, USA. 27-30 January 2016
}

\section{Background}

The presence of myocardial fibrosis in hypertrophic cardiomyopathy (HCM) is associated with a wide range of adverse outcomes including ventricular arrhythmia and sudden death in adults. Its presence suggests an adverse prognosis and may provide important therapeutic guidance. Native $\mathrm{T} 1$ can be an alternative to routinely used late gadolinium enhancement and has a potential to provide a non-contrast alternative in children.

\section{Methods}

Our cohort population consisted of 21 patients (mean age, $14.1 \pm 4.6$ years; range $2-21$ years) with hypertrophic cardiomyopathy undergoing routine clinical cardiac magnetic resonance (CMR). The diagnosis of HCM was based on the demonstration of a non-dilated hypertrophic left ventricle (LV) in the absence of increased LV stress or another cardiac or systemic disease that could result in a similar magnitude of hypertrophy. Twelve subjects (mean age, $15.5 \pm 1.6$ years; range 2 21 years) with low pre-test likelihood of cardiomyopathy, without any known cardiovascular disease, congenital or acquired by history, echocardiography, or CMR served as controls. In all subjects, breath hold, ECG triggered, 2D MOLLI TrueFISP data was acquired in short axis locations at base, mid-chamber, and apex. Native (non-contrast) myocardial T1 maps were calculated a $\mathrm{T} 1$ was quantified based in the 16-segment AHA model.

\section{Results}

Global native T1 (averaged over the entire LV) in patients with HCM was significantly increased compared to controls $(\mathrm{T} 1=1023.3 \pm 41.8 \mathrm{~ms}$ vs. $963.5 \pm 16.1 \mathrm{~ms}$, $\mathrm{p}<0.001)$. Regional analysis demonstrated significantly elevated (3.8 to $7.6 \%$ differences, $\mathrm{p}<0.05)$ native $\mathrm{T} 1$ in

Northwestern University, Chicago, IL, USA all 16 AHA segments. A T1 of $>990$ msec yielded a sensitivity of $90 \%$ and specificity of $90 \%$ to identify patients with HCM $(\mathrm{p}<0.05)$. There was a modest but significant correlation between native T1 and indexed LV mass $(r=0.36, p=0.03)$. No correlation was identified between native $\mathrm{T} 1$ and heart rate, LV ejection

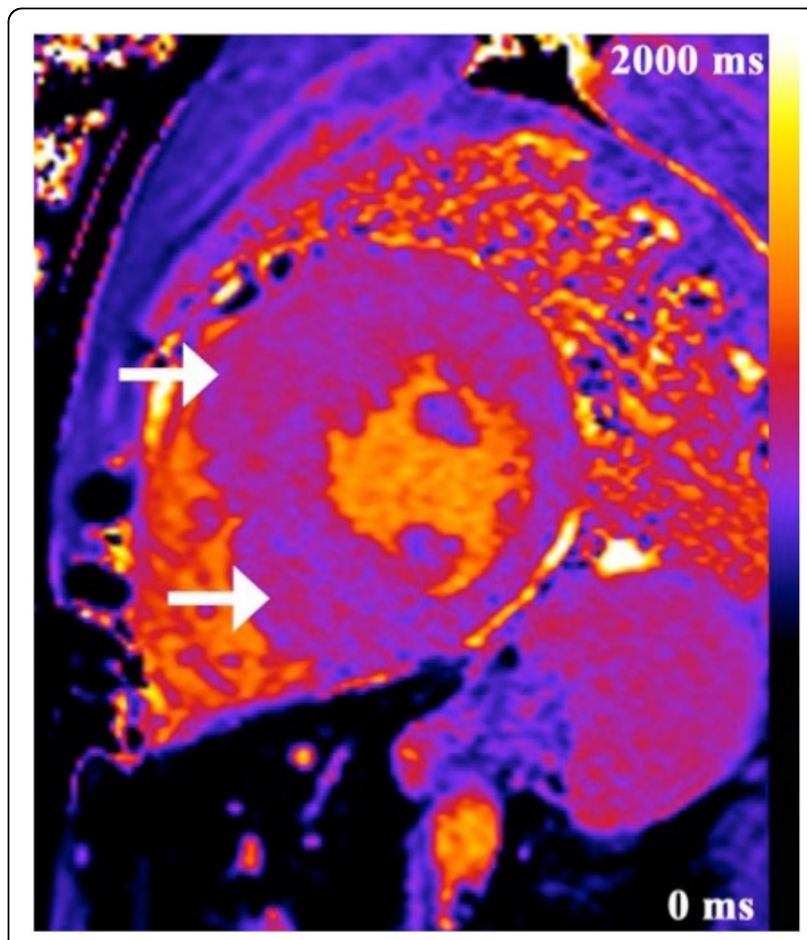

Figure 1 Example of color-coded T1 map in a patient with hypertrophic cardiomyopathy (HCM). Sixteen-year-old male patient presented with palpitations and was diagnosed with HCM on echocardiography. Maximum single wall thickness was $2.6 \mathrm{~cm}$ in the mid-chamber antero-septal region. Color-coded T1 map in midchamber short axis shows patchy areas of increased $\mathrm{T} 1$ relaxation time (arrows), more marked in hypertrophic segments. Color scale ranges from $0 \mathrm{~ms}$ to $2000 \mathrm{~ms}$. 
fraction, indexed end-diastolic, and end-systolic volume $(\mathrm{p}=0.11,0.82,0.45$, and 0.64$)$. There was no significant difference in $\mathrm{T} 1$ values between HCM patients without and with late gadolinium enhancement $(\mathrm{p}=0.07)$.

\section{Conclusions}

Global and segmental native T1 values were elevated in patients with HCM, but did not correlate with parameters of LV structure and function. Native T1 of LV myocardium in children and young adults can be used as a non-invasive tool to identify patients with HCM with a high sensitivity and specificity. Further work should determine whether T1 mapping can guide cardiac risk stratification for children and young adults with HCM.

Published: 27 January 2016

doi:10.1186/1532-429X-18-S1-Q44

Cite this article as: Parekh et al:: Native T1 mapping in children and

young adults with hypertrophic cardiomyopathy. Journal of

Cardiovascular Magnetic Resonance 2016 18(Suppl 1):Q44.
Submit your next manuscript to BioMed Central and take full advantage of:

- Convenient online submission

- Thorough peer review

- No space constraints or color figure charges

- Immediate publication on acceptance

- Inclusion in PubMed, CAS, Scopus and Google Scholar

- Research which is freely available for redistribution

Submit your manuscript at www.biomedcentral.com/submit
C Biomed Central 